\title{
Extraction and FTIR characterization of chitosan from Portunus pelagicus (Linnaeus, 1758) shell wastes
}

\author{
S. Vigneshwari and V. Gokula \\ PG and Research Department of Zoology, National College, \\ Tiruchirapalli-620 001, Tamil Nadu, India
}

\begin{abstract}
In the present study, Chitin, a natural polymer, is extracted from the Portunus pelagicus shell wastes. Chitosan was prepared from chitin. Yield of both chitin and chitosan was determined and yield percentage was calculated. Physico-chemical characterization of chitosan was performed by determining moisture and ash content. Fourier Transform Infrared spectroscopy (FTIR) was done to show the functional groups of extracted chitosan. The characteristic peaks confirmed the high quality and purity of chitosan. Degree of deacetylation was calculated from FTIR spectrum which showed that Portunus pelagicus shell wastes can be used to extract chitin and chitosan.
\end{abstract}

Keywords: Chitosan, Polymer, Moisture, Ash, FTIR spectrum

\section{Introduction}

Since antiquity, fishing and seafood consumption has played an important role in coastal regions of Tamil Nadu. Utilization of marine resources for human consumption has increased rapidly worldwide. The shell fish industry is operative among all the costal countries and contributes hugely to the food delicacies. During the processing of prawns, shrimps, crabs and lobsters mostly the meat is taken, while the shell and head portions are generated as wastes. This results in the generation of a huge amount of wastes throughout the world (Tarafdar and Biwas, 2013). It is estimated that the shell-fish industry produces about 60,000 80,000 tons of waste. The disposal of such an enormous amount of waste has become a serious environmental concern. Although these wastes are biodegradable but the rate of degradation of a large amount of waste generated per processing operation is comparatively slow (Prashanth and Tharanathan, 2007). This results in accumulation of shell wastes that leads to obnoxious smell and attract pathogenic insects, flies and rodents, thus creating an unhygienic atmosphere. The immediate solution to this problem seems to be quick recycling of the crustacean shells generated and extraction of commercially viable substances that can be further used in other applications. Massive amounts of shells have been abandoned as wastes from worldwide seafood companies. The processing of human food production also causes $50-70 \%$ shells and residual meat (Basosidik et al., 2013). Seafood processing industry in India is contributing tonnes and tonnes of waste materials and among them shrimp and crab waste occupy more than a lakh tonnes every year (Philip and Nair, 2006). In the past two decades, scientists have been researching on the recovery of valuable products from shell wastes.

After cellulose, chitin is the second most abundant natural biopolymer found in nature. Chitin is a linear biopolymer composed of 2-acetamido-2deoxy-D-glucopyranose units linked by $\beta$ glycosidic bonds (Subhapradha et al., 2013). Chitin is usually isolated from the exoskeleton of crustaceans and more particularly from shrimps and crabs (Vigneshwari and Gokula 2018a, b). It is also found in the cuticle of insects and cell wall of fungi (Ausa Chandumpai et al., 2004). Chitin is insoluble in most of the solvents, because of its compact structure. The most common derivative of chitin is chitosan, which is a natural polysaccharide comprising of copolymers of glucosamine and $\mathrm{N}$-acetylglucosamine (Dutta, 2004), and can be obtained by the partial deacetylation of chitin. When the degree of deacetylation (DDA) reaches higher than 50\%, chitosan becomes soluble in acidic aqueous solutions and it behaves as a cationic polyelectrolyte (Nesr et al., 2013). Over the past several years, chitinous polymers, especially chitosan, has received increased attention as one of the most promising renewable polymeric materials for its extensive application in the pharmaceutical and biomedical industries (Barwin Vino et al., 2012). Chitosan has received 
extensive applications in industrial and biomedical areas such as paper production, textile finishes, photographic products, cements, heavy metal chelation, waste water treatment and film formation (Ravi Kumar, 1999).

To reduce environmental pollution in the coastal areas and to recover useful by-product out of those biodegradable wastes, the present study aims to extract and characterize chitosan from Portunus pelagicus shell wastes collected from Mimisal, Tamil Nadu, India.

\section{Materials and Methods}

Extraction of chitin and chitosan from crab shell wastes

Demineralization

$20 \mathrm{gm}$ of sample powder was demineralised with $300 \mathrm{ml}$ of $2 \mathrm{~N} \mathrm{HCl}$ at $80{ }^{\circ} \mathrm{C}$ for 24 hours with constant stirring in a magnetic stirrer at $800 \mathrm{rpm}$ and then filtered. The filtrate was again and again washed with distilled water and filtered till the liquid showed neutral $\mathrm{pH}$. The filtrate was then dried in hot air oven and weighed following the method of Takiguchi (1991a).

\section{Deproteinization}

The filtrate obtained after demineralization was then deprotenized with $300 \mathrm{ml}$ of $1 \mathrm{~N} \mathrm{NaOH}$ at 80 ${ }^{\circ} \mathrm{C}$ for 24 hours with constant stirring in a magnetic stirrer at $800 \mathrm{rpm}$ and then filtered. The filtrate was again and again washed with distilled water and filtered till the liquid showed neutral $\mathrm{pH}$. The obtained filtrate was chitin and it was dried in hot air oven and weighed following the method of Takiguchi (1991b).

\section{Deacetylation (Conversion of Chitin into Chitosan)}

Chitosan was extracted from chitin through partial deacetylation process following the method of Takiguchi (1991b). Chitin was deacetylated with $40 \% \mathrm{NaOH}$, heated for 6 hours at $110^{\circ} \mathrm{C}$ with constant stirring in a magnetic stirrer at $800 \mathrm{rpm}$ and then filtered. To this filtrate $10 \%$ acetic acid was added and stored for $12 \mathrm{~h}$ at room temperature with constant stirring. The dissolved sample was reprecipitated by adding $40 \% \mathrm{NaOH}$, adjusting to $\mathrm{pH}$ 10. The obtained filtrate chitosan was dialyzed by deionized water to a $\mathrm{pH}$ of 6.5 and centrifuged at $10,000 \mathrm{rpm}$ for $10 \mathrm{~min}$ and freeze dried.

\section{Physicochemical characterization of extracted chitosan}

\section{Determination of yield of chitin and chitosan}

The yield of the chitosan was obtained by comparing the weight of the raw material to the weight of the obtained chitin and chitosan after treatment using following formula (Mohanasrinivasan et al. 2013).

$$
\text { Yield } \%=\frac{\text { Weigt of the sample }}{\text { Weight of the raw material }} \times 100
$$

\section{Determination of Moisture and Ash Content in} Chitosan

The moisture content of extracted chitosan was determined following the method of AOAC, (1990). The water mass of the sample was estimated by drying of $1 \mathrm{~g}$ of the sample in a pre-weighed container and measured. The initial weight was noted. The container was placed in a hot air oven at $600^{\circ}$ for 6 hours until constant weight was obtained and final weight was also noted.

$$
\text { Moisture (\%) }=\frac{\text { Wet weight }- \text { Dry weight }}{\text { Wet weight }} \times 100
$$

Ash content of the sample was estimated following the method of AOAC (1990) by incinerating $1 \mathrm{~g}$ chitosan in pre-weighed tarred crucibles. The sample was heated in the muffle furnace at $600^{\circ} \mathrm{C}$ for a period of 6 hours. The crucibles were allowed to cool and weights of the residues were noted.

$$
\operatorname{Ash}(\%)=\frac{\text { Wet weight }- \text { Dry weight }}{\text { Wet weight }} \times 100
$$

\section{Fourier Transform Infrared Spectroscopy (FTIR)} analysis

The FTIR spectrum of the extracted chitosan was determined according to the method of Mohammed et al. (2013). For the preparation, 1\% w/v of chitosan was dissolved in $1 \%$ acetic acid and dried. The fine powder was thoroughly mixed with potassium bromide and made into $\mathrm{KBr}$ pellets. The FTIR spectra were recorded using a Thermo Nicolet Avatar 370 spectrophotometer in the frequency range of $400-4000 \mathrm{~cm}^{-1}$. Each spectrum is an average of 64 scans with a resolution of $2 \mathrm{~cm}^{-1}$.

\section{Degree of Deacetylation}

The DD of extracted chitosan was determined using FTIR spectrum with frequency of 4,000 to $400 \mathrm{~cm}^{-1}$ (Baxter et al., 1992; Abouzeed et al. 2015) using following equation. 


$$
\begin{gathered}
D A \%=100-\left(A_{1637} / A_{3430}\right) \times 100 \\
D D \%=(100-D A \%)
\end{gathered}
$$

\section{Results}

Chitin was extracted from the shell wastes of Portunus pelagicus followed by $\mathrm{N}$-deacetylation to obtain chitosan. The yield percentage was given in Table. 1. In our study, from the $20 \mathrm{~g}$ of the raw material $7.41 \mathrm{~g}$ of chitin was yielded and the yield percentage was calculated as $62.95 \%$. From chitin, 3 $\mathrm{g}$ chitosan was extracted and the yield percentage was calculated as $85 \%$. Moisture and ash percentage of chitosan was $32.9 \%$ and $1.6 \%$ respectively (Table. 2). Physicochemical characterization of chitosan by FTIR technique was carried out to identify the functional groups present in it and to calculate the degree of deacetylation process.

The FTIR showed effective major peaks at the range of $3430.48,3268.53,3110.11,2928.17$, $2892.45, \quad 2515.09, \quad 1794.88, \quad 1627.43,1457.03$, $1323.65,1261.84,1204.76, \quad 1156.73,1071.37$, 1034.04, 954.53, 873.36, $751.50 \mathrm{~cm}^{-1}$. The infrared characteristic peaks and the functional groups were presented in Table. 3 and Figure. 1. In the present study, extracted chitosan showed the alcohol $\mathrm{O}-\mathrm{H}$ stretching band at $3430.48 \mathrm{~cm}^{-1}$ and the $\mathrm{N}-\mathrm{H}$ stretching band of free amine groups was depicted in the range of $3268 \mathrm{~cm}^{-1}$ and $3110.11 \mathrm{~cm}^{-1}$. The band observed at 2,928.17 and 2,892.45 cm-1 corresponds to asymmetric stretching of $\mathrm{CH} 3$ and $\mathrm{CH} 2$. The intensive peak appeared at $1457.03 \mathrm{~cm}-1$ corresponds to $\mathrm{NH}_{2}$ bending vibration of amine group is a characteristic feature of chitosan polymer. In addition, other bands in the region of 1323.65$1457.03 \mathrm{~cm}^{-1}$, are attributed to the bending vibrations of the methyl groups. The band at $1071.37 \mathrm{~cm}^{-1}$ was identified as $\mathrm{C}-\mathrm{O}$ stretching band. The out plane bending $-\mathrm{OH}$ vibrations are observed at $712.45 \mathrm{~cm}^{-1}$.

Table. 1 Yield \% of chitin and chitosan

\begin{tabular}{|l|l|l|l|l|}
\hline $\begin{array}{l}\text { Shell } \\
\text { wastes } \\
(\mathrm{g})\end{array}$ & $\begin{array}{l}\text { Chitin } \\
(\mathrm{g})\end{array}$ & $\begin{array}{l}\text { Chitin } \\
\text { Yield } \\
\%\end{array}$ & $\begin{array}{l}\text { Chitosan } \\
(\mathrm{g})\end{array}$ & $\begin{array}{l}\text { Chitosan } \\
\text { Yield \% }\end{array}$ \\
\hline 20 & $\begin{array}{l}7.41 \\
0.44\end{array}$ & 62.95 & $3 \pm 0.29$ & 85 \\
\hline
\end{tabular}

Values are expressed as Mean \pm S.D $(n=6)$

Table. 2 Physicochemical characterization of Chitosan

\begin{tabular}{|l|l|}
\hline Parameters & Values \\
\hline Moisture (\%) & $32.9 \pm 0.01$ \\
\hline Ash $(\%)$ & $1.6 \pm 0.01$ \\
\hline $\begin{array}{l}\text { Degree of deacetylation } \\
(\%)\end{array}$ & 84.13 \\
\hline
\end{tabular}

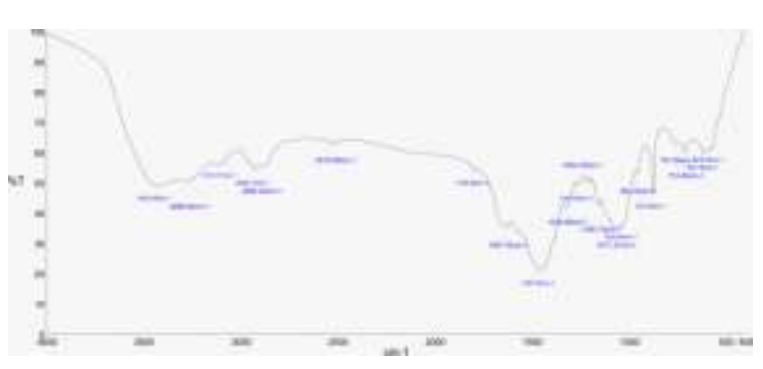

Fig. 1 FTIR Spectra of Chitosan

Table. 3 FTIR spectral peaks of extracted

\begin{tabular}{|c|c|c|c|}
\hline S.No & $\begin{array}{l}\text { Wave } \\
\text { Number } \\
\left(\mathrm{cm}^{-1}\right)\end{array}$ & Absorption Bands & $\begin{array}{l}\text { Nature of } \\
\text { the Peaks }\end{array}$ \\
\hline 1. & 3430.48 & $\begin{array}{ll}\begin{array}{l}\text { Hydroxyl } \\
\text { stretching }\end{array} & \mathrm{OH} \\
\end{array}$ & Broad \\
\hline 2. & 3268.53 & $\begin{array}{l}\mathrm{H} \text { bonded } \mathrm{NH} 2 \\
\text { stretching }\end{array}$ & Broad \\
\hline 3. & 2928.17 & $\begin{array}{ll}\begin{array}{l}\text { Aliphatic } \\
\text { stretching }\end{array} & \mathrm{CH}_{3} \\
\end{array}$ & Sharp \\
\hline 4. & 2892.45 & $\begin{array}{ll}\begin{array}{l}\text { Aliphatic } \\
\text { stretching }\end{array} & \mathrm{CH}_{2} \\
\end{array}$ & Medium \\
\hline 3. & 1627.43 & $\begin{array}{l}\text { Amine I } \quad \mathrm{C}=\mathrm{O} \\
\text { stretching }\end{array}$ & Sharp \\
\hline 4. & 1457.03 & $\begin{array}{lll}\begin{array}{l}\text { Amine } \\
\text { bending }\end{array} & \mathrm{NH}_{2} \\
\end{array}$ & Sharp \\
\hline 5. & 1261.84 & $\begin{array}{l}\mathrm{CH}_{3} \quad \text { stretching } \\
\text { asymmetrical }\end{array}$ & Sharp \\
\hline 6. & 1204.76 & $\begin{array}{l}\mathrm{CH}_{2} \quad \text { stretching } \\
\text { asymmetrical }\end{array}$ & Sharp \\
\hline 7. & 1071.37 & $\mathrm{NH}$ bending & Medium \\
\hline 8. & 1034.04 & Ring bending & Medium \\
\hline 9. & 954.53 & Ring bending & Medium \\
\hline 10. & 873.36 & $\begin{array}{l}\mathrm{N}=\mathrm{O}=\mathrm{N} \text { bending } \\
\text { vibration }\end{array}$ & Sharp \\
\hline 11. & 751.50 & C-O-C stretching & Sharp \\
\hline 12. & $\begin{array}{l}607.55- \\
578.42\end{array}$ & $\begin{array}{l}\text { Pyranose bending } \\
\text { vibration }\end{array}$ & Sharp \\
\hline
\end{tabular}
chitosan

\section{Discussion}

According to Cauchie, (1997) concerning the production of predominant biopolymer of the sea chitin produced by crustaceans, molluscs, insects were 100 billion tones every year. The yield\% of chitosan from Scylla serrata was $38.23 \%$ (Kiruba et al. 2013) and Scylla tranquebarica was $10.74 \%$ (Thirunavukkarasu and Shanmugam, 2009) which were less when compared with our chitosan yield\% from Portunus pelagicus. Yen et al., 2009 have showed crab chitosan $\%$ were in the range of $30-32 \%$. Islam et al. 2011 showed that yield\% was $15.21 \%$ and Mohanasrinivasan et al. 2013 as $17 \%$ only from 
shrimp shell wastes. Our results have proved the highest yield of chitosan from Portunus pelagicus shell wastes. Thus, chitosan, an economically and biologically valuable product, was effortlessly extracted from low cost raw material. Moisture content less than $10 \%$ is more suitable for commercial purposes. The lower value of the ash content indicates the purity of the sample that complete demineralization and deproteinization have took place (Mohanasrinivasan et al. 2013). Moisture and ash content were relatively high when compared with other studies (Felicity Burrows et al. 2007; Sarbon et al. 2014; Walke et al. 2014). Chitosan is produced from chitin by partial N-deacetylation process with a strong alkaline solution like sodium hydroxide (Acharyalu et al. 2013).

The FTIR spectrum of extracted chitosan showed a larger intensity at $1457.03 \mathrm{~cm}^{-1}$ than at $1627.43 \mathrm{~cm}^{-1}$ which revealed effective deacetylation has took place by removing acetamido $\left(\mathrm{CH}_{3} \mathrm{CONH}\right)$ groups and forming more amine $\left(\mathrm{NH}_{2}\right)$ groups (Limam et al. 2011; Zvezdova and Uzov, 2012). Our FTIR spectrum are in accordance with the results of Chakraborty and Ghosh, (2010), Walke et al. (2014), Gokilavani et al. (2014), Sakthivel et al. (2015) and Thirunavukkarasu and Shanmugam, (2009).

\section{Conclusions}

Chitin is enormously available in the exoskeleton of crustaceans and in our study chitosan was extracted from Portunus pelagicus shell wastes with high yield\%. This can be recommended for large scale production of chitosan of commercial standard. By extracting chitosan from shell wastes, pollution due to dumping of shell wastes along the coastal can be minimised. This extracted chitosan may be widely used in biomedical and pharmaceutical companies due to its versatile properties.

\section{Acknowledgments}

Authors are thankful to the Principal and the Management, National College (Autonomous), Trichy -620001 for providing the necessary facilities.

\section{References}

[1] Abouzeed AS, Shaltout OE, Ibrahim, SM, Attia RS, Aboul-yazeed AM. Production and evaluation of some bioactive compounds extracted from Squilla (Oratosquilla massavensis) Shells. American Journal of Life Sciences, 3(6-1), 38-44, (2015).

[2] Acharyulu R, Gomathi T, Sudha PN. Physicochemical characterization of cross linked chitosan- polyacrylonitrile polymer blends. Der Pharmacia Lettre, 5(2):354-363, (2013).

[3] AOAC. Association of Official Analytical Chemists. Official Methods of Analysis. 15th edition, Washington, DC, (1990).

[4] Basosidik S, Pankeaw P, Hoonnivathana E, Limsuwan P, Naemchanthara K. Preparation and structure of chitosan from waste sources. Proceeding in Science and Engineering, 530-535, (2013).

[5] Baxter A, Dillon M, Anthony Taylor KD, Roberts GAF. Improved method for (IR) determination of the degree of $\mathrm{N}$-acetylation of chitosan. International Journal of Biological Macromolecules, 14: 166-169, (1992).

[6] Burrows F, Louime, C, Abazinge M, Onokpise O. Extraction and evaluation of chitosan from crab exoskeleton as a seed fungicide and plant growth enhancer. American Eurasian Journal Agriculture Environment Sciences, 2(2):103-111, (2007).

[7] Cauchie HM. An attempt to estimate crustacean chitin production in the hydrosphere. In: Advances in Chitin Science: Vol 2: (Domard A, GAF Roberts, KM Varum, eds): Jacques Andre Publisher, Lyon, France, pp: 32, (1997).

[8] Chakraborty S, Ghosh U. Production of chitosan from marine trash crustaceans and its application in mercury removal from sea water. International Journal of Chemical and Analytical Science, 1(8):186-192, (2010).

[9] Chandumpai N, Singhpibulporn N, Faroongsarng D, Sornprasit P. Preparation and physico-chemical of chitin and chitosan from the pens of the squid species, Loligo lessoniana and Loligo formosana. Carbohydrate Polymers, 58:467-474, (2004).

[10] Dutta PK, Dutta J, Tripathi VS. Chitin and Chitosan: Chemistry, properties and applications. Journal of Scientific \& Industrial Research, 20-31, (2004).

[11] Gokilavani S, Vijayabharathi V, Parthasarathy R. Physico-chemical characteristics and antibacterial activity of chitosan extracted from shell of crab Paratelphusa hydrodromous. Asian Journal of Research in Pharmaceutical Sciences, 4(3):125-128, (2014).

[12] Islam M, Masumb SM, Mahbuba KR, Haquea Z. Antibacterial activity of crab-chitosan against Staphyloccus aureus and Escherichia coli. Journal of advanced Science Researh, 2(4):63-66, (2011).

[13] Kiruba A, Uthayakumar V, Munirasu S, Ramasubramanian V. Extraction, characterization and physico chemical properties of chitin and chitosan from Mud crab shell (Scylla serrata). Indian Journal of Applied research, 3(8):44-46, (2013).

[14] Limam Z, Selmi S, Sadok S, El Abed A. Extraction and characterization of chitin and chitosan from crustacean by-products: Biological and physicochemical properties. African Journal of Biotechnology, 10(4): 640-647, (2011).

[15] Mohammed MH, Williams PA, Tverezovskaya O. Extraction of chitin from prawn shells and conversion to low molecular mass chitosan. Food Hydrocolloids, 31:166-171, (2013).

[16] Mohanasrinivasan V, Mishra M, Paliwal J, Singh S, Selvarajan E, Suganthi V, Subathra Devi C. Studies on heavy metal removal efficiency and antibacterial 
activity of chitosan prepared from shrimp shell waste. 3 Biotech, 4(2):167-175, (2013).

[17] Philip M, Nair KGR. Ensilation of shrimp waste by Lactobacillus fermentum. Fishery Technology, 43:5964, (2006).

[18] Prashanth. KVH, Tharanathan RN. Chitin/chitosan: modifications and their unlimited application potential- an overview. Trends in Food Science and Technology, 18:117-131, (2007).

[19] Ravi Kumar MNV. Chitin and chitosan fibres-Review. Bulletin of Materials Science, 22(5); 905-915, (1999).

[20] Sakthivel D, Vijayakumar N, Anandan V. Extraction of Chitin and Chitosan from Mangrove Crab Sesarma plicatum from Thengaithittu Estuary Pondicherry Southeast Coast of India. International Journal of Pharmacy and Pharmaceutical Sciences, Human, 4 (1):12-24, (2015).

[21] Sarbon NM, Sandanamsamy S, Kamaruzaman, SF, Ahmad F. Chitosan extracted from mud crab (Scylla olivicea) shells: physicochemical and antioxidant properties. Journal of Food Science Technology, 52(7):4266-4275, (2015).

[22] Subhapradha N, Ramasamy P, Shanmugam V, Madeswaran P, Srinivasan A, Shanmugam A. Physicochemical characterisation of $\beta$-chitosan from Sepioteuthis lessoniana gladius. Food Chemistry, 141:907-913, (2013).

[23] Takiguchi Y. Physical properties of chitinous materials. In R. H. Chen \& H.C. Chen (Eds.), Advances in chitin science. Proceeding from the third Asia Pacific Chitin, Chitosan-Jikken manual (Vol. 3, pp.1-7).Japan: Gihodou Shupan Kabushki Kasisha, (1991a).

[24] Takiguchi, Y. Preparation of chitosan and partially deacetylated chitin. In A. Otakara \& M. Yabuki (Eds.),
Chitin, Chitosan-Jikken manual (chapter 2, pp. 9-17). Japan: Gihodou Shupan Kabushki Kasisha, (1991b).

[25] Tarafdar A, Biswas G. Extraction of chitosan from prawn shell wastes and examination of its viable commercial applications. International Journal on Theoretical and Applied Research in Mechanical Engineering, 2(3):17-24, (2013).

[26] ThirunavukkarasuN, Shanmugam A. Extraction of chitin and chitosan from mud crab Scylla tranquebarica (Fabricius, 1798). International Journal on Applied Bioengineering, 4(2):31-33, (2009).

[27] Vigneshwari, S and Gokula, V. Proximate composition of cooked meat and exoskeleton of Potunus pelagicus (Linnaeus, 1758). RJLBPCS 4(5): 574-585 (2018a)

[28] Vigneshwari, S and Gokula, V. Antibacterial Efficacy of Chitosan and Its Mediated Silver Nanoparticles from Shell Wastes of Portunus Pelagicus. Int J Recent Sci Res. 9(3), pp. 24933-24938. DOI: http://dx.doi.org/10.24327/ijrsr.2018.0903.1756 (2018b)

[29] Walke S, Srivastava G, Nikalje M, Doshi J, Rakesh Kumar, Satish Ravetkar, Doshi, P. Physicochemical and functional characterization of chitosan prepared from shrimp shells and investigation of its antibacterial, antioxidant and Tetanus toxoid entrapment efficiency. International Journal of Pharmceutical sciences Review and Research, 26(2):215-225, (2014).

[30] Yen MT, Yang JH, Mauc JL. Physicochemical characterization of chitin and chitosan from crab shells. Carbohydrate Polymers, 75:15-21, (2009).

[31] Zvezdova D, Uzov C. Determination of degree of deacetylation of chitin and chitosan by X-Ray diffraction. Management and Education, 8(4): 85-89, (2012). 